\title{
Rational Expectations in Two-way Game
}

\author{
Gang Hao \\ School of Statistics \\ Southwestern University of Finance and Economics \\ Chengdu, China \\ ganghao@swufe.edu.cn
}

\begin{abstract}
Facing with the private information asymmetry, transaction is successfully delivered and will benefit the bilateral parties who can get maximized utility, but the automatic implementation of trading need to satisfy the corresponding conditions. Model built by strategic game method is applied to depict the trading game process under given the linear strategy space of both parties, finally some useful conclusions are introduced.
\end{abstract}

Keywords-Incomplete information; static game; Two-way game; agent

\section{INTRODUCTION}

By Wilson (1969), Ross (1973), Mirrlees(1974), Holmstrom (1979) , rossmann and hart (1983) create a entrust the agency theory and application of the model analysis, the main solution to entrust an agency relationship exists in the problem of asymmetric information. Information asymmetry is a common phenomenon that exists in economic and social backgrand, for example, the downstream retailers closer to consumers than the upstream suppliers, and retailers have mastered more or more accurate market information. Gan, Sethi \& Yan (2000) study the importance of supply chain coordination, and put forward by designing a menu of contracts to achieve coordination under the condition of asymmetric information to . Corbett \& x. De Groote (2000) studied under the condition of asymmetric information, the supplier how to design the optimal discount strategy problem. Corbett \& d. Zhou \& c.s. Tang (2004) studied under the condition of asymmetric information, the supplier is how to obtain more reliable buyers through the consumption of information, thus providing more.But those papers did not consider the role of bargaining power in this situation.

We model the problem as a decision process of rational expectations in two-way game and solve it using game theory.

\section{MODEL ANALYSIS}

Consider two agent $\mathrm{i}$ and $\mathrm{j}$ for a deal, they each have some private information, the transaction price $\mathrm{w}$ is not specified directly, and completed by both bidding. The pricing rule is: an dominated agent $\mathrm{i}$ give transaction price $w_{i}$. agent $\mathrm{j}$ keep his own trading prices for private information, if $w_{i} \leq w_{j}$, that deal with price can be given as

$$
w=w_{j}+k\left(w_{i}-w_{j}\right)
$$

among it $k \in[0,1]$, it represents the dominant agent of bargaining power; If $w_{i}>w_{j}$, the deal will be cancellwed. So this is a state of imperfect information dynamic strategy game. The agent $\mathrm{j}$ first according to benefit maximization to do decision-making, leading agent observed psychological price of agent $\mathrm{j}$, bid processes according to their types on the basis of the linear rule.

The dominant agent for the deal is valued at private information as $v_{i}$, agent $\mathrm{j}$ values $v_{j}$ at private information, and observe the range of uniform distribution of [0,1]. If the transaction is successful, the dominant agent can get the utility $v_{i}-w$; If the deal is not successful, the utility of 0 . If an order is committed, then the agent $\mathrm{j}$ get utility $w-v_{j}$; If the transaction fails, his utility is 0 .

This is a strategy of incomplete information static game we according to harsanyi transformation method, can the introduction of "natural" to decide business valuation type on both sides, including "natural" gives out the type of agent $i$, and only tell hiself; "Nature" also give agent $\mathrm{j}$ type, and only to inform agent $\mathrm{j}$ in the same way . both parties don't know The types of each others. Agent I and $\mathrm{j}$ make bid strategy, depending on their valuation the types of both parties. In the static strategy game, finding out their types of dependencies, and bid strategy $w_{i}\left(v_{i}\right)$ and $w_{j}\left(v_{j}\right)$, and then making comparison in different equilibrium strategies.

We assume that the agent i's bid strategy is the function $w_{i}\left(v_{i}\right)$ with knowing agent j's every possible types. the same way of that agent $\mathrm{j}$ is a strategy of function $w_{j}\left(v_{j}\right)$ with knowing agent i's every possible types. if the following two conditions are set up, the strategy combination $\left\{w_{i}\left(v_{i}\right) w_{j}\left(v_{j}\right)\right\}$ will be the strategy of Nash equilibrium of the game.

The decision-making models of the agent $\mathrm{i}$ and $\mathrm{j}$ as follow :

$$
\left\{\begin{array}{l}
\max _{w_{i}}\left[v_{i}-k w_{i}-(1-k) w_{j}\right] p\left(w_{i}<w_{j}\left(v_{j}\right)\right) \\
\max _{w_{j}}\left[k w_{i}+(1-k) w_{j}-v_{j}\right] p\left(w_{i}\left(v_{i}\right)<w_{j}\right)
\end{array}\right.
$$


Among them and said agent $\mathrm{i}$ and $\mathrm{j}$ estimate probability clinch a deal. Assume that the valuation of bidding strategy for linear function of:

$$
w_{i(\text { or } j)}\left(v_{i(\text { or } j)}\right)=a_{i(\text { or } j)}+b_{i(\text { or } j)} v_{i(\text { or } j)}, b_{i(\text { or } j)}>0
$$

Calculation of probability and mathematical expectation:

$$
\begin{aligned}
p\left(w_{i}\left(v_{i}\right)<w_{j}\right) & =p\left(a_{i}+b_{i} v_{i}<w_{j}\right) \\
& =p\left(v_{i}<\left(w_{j}-a_{i}\right) / b_{i}\right) \\
& =\left(w_{j}-a_{i}\right) / b_{i}
\end{aligned}
$$

And

$$
\begin{aligned}
p\left(w_{i}<w_{j}\left(v_{j}\right)\right) & =p\left(w_{i}<a_{j}+b_{j} v_{j}\right) \\
& =p\left(v_{j}>\left(w_{i}-a_{j}\right) / b_{j}\right) \\
& =\left(b_{j}+a_{j}-w_{i}\right) / b_{j}
\end{aligned}
$$

Bring formula (4) and (5) into (2):

$$
\left\{\begin{array}{l}
\max _{w_{i}}\left[v_{i}-k w_{i}-(1-k) w_{j}\right] \cdot\left(b_{j}+a_{j}-w_{i}\right) / b_{j} \\
\max _{w_{j}}\left[k w_{i}+(1-k) w_{j}-v_{j}\right] \cdot\left(w_{j}-a_{i}\right) / b_{i}
\end{array}\right.
$$

By the first-order conditions could get:

$$
\left\{\begin{array}{l}
w_{i}=\frac{1}{3}\left(\frac{-a_{i}-v_{j}}{k}+a_{i}+2 k a_{j}+2 k b_{j}\right)+\frac{2}{k} v_{i} \\
w_{j}=\frac{-2 a_{i}+v_{i}+2 k a_{i}+k a_{j}+k b_{j}}{3 k-3}-\frac{2}{3 k-3} v_{j}
\end{array}\right.
$$

Comprising the coefficient of (6) and (3) , we have

$$
\left\{\begin{array}{l}
a_{i}=\frac{1}{3}\left(\frac{-a_{i}-v_{j}}{k}+a_{i}+2 k a_{j}+2 k b_{j}\right), b_{i}=\frac{2}{k} \\
a_{j}=\frac{-2 a_{i}+v_{i}+2 k a_{i}+k a_{j}+k b_{j}}{3 k-3}, b_{j}=\frac{2}{3(1-k)}
\end{array}\right.
$$

So, we can get

$$
\left\{\begin{array}{l}
a_{i}=\frac{2 k a_{j}+2 k b_{j}-v_{j}}{2 k+1}, b_{i}=\frac{2}{k} \\
a_{j}=\frac{v_{i}+2 k a_{i}+k b_{j}-2 a_{i}}{2-3 k^{2}}, b_{j}=\frac{2}{3(1-k)}
\end{array}\right.
$$

Put (7) into (1) and we can get the resulting coefficients as follows:

$$
\begin{gathered}
w=\left(\frac{4 k^{2}}{3(1-k)(2 k+1)}+\frac{2 k}{3\left(2-3 k^{2}\right)}\right)+ \\
\frac{2(1-k)^{2}}{2-3 k^{2}} a_{i}+\frac{2 k^{2}}{2 k+1} a_{j}+\frac{(5-6 k)(1+k)}{2-3 k^{2}} v_{i}+\frac{k+2}{3(2 k+1)} v_{j}
\end{gathered}
$$

\section{COMPARATIVE STATIC ANALYSIS}

From the analysis from the section two, we can get some important conclusions as follows:

Theorem 1: the dominant agent $\mathrm{i}$ will always be an overreaction in the transaction.

Theorem 2:

(1) If $k>1 / 3$, agent $\mathrm{j}$ will do the excessive reaction in the transaction;

(2) If $k \leq 1 / 3$, agent $\mathrm{j}$ will be cautious response in the transaction.

By observing the type (6) and sensitive coefficient of types of both parties, theorem 1 and theorem 2 above, can be easily derived.

Theorem 3:

(1) If $\sqrt{2 / 3}>k>0$, the resulting transaction price will be more sensitive to the type of the dominant agent $i$;

(2) If $1>k>\sqrt{2 / 3}$, the resulting transaction price will be more sensitive to the type of the dominant agent $i$;

(3) Whatever the value of $\mathrm{k}$, the resulting transaction price will always be cautious to the type of the agent $\mathrm{j}$.

Proof: By observing the type (8) and sensitive coefficient of types of both parties relative to the resulting transaction price, sensitive coefficient with the type of the dominant agent $i$ is

$$
\frac{(5-6 k)(1+k)}{2-3 k^{2}}
$$

Let it is larger than 1 , we can get:

$$
\begin{aligned}
& \text { if } 2-3 k^{2}>0,0>3 k^{2}+k-3 \\
& \text { if } 2-3 k^{2}<0,0<3 k^{2}+k-3
\end{aligned}
$$

And 


$$
\sqrt{\frac{2}{3}}>k>0
$$

So we can prove the first two sub-conclusions in Theorem 3. Sensitive coefficient with the type of the agent $\mathrm{j}$ is

$$
\frac{k+2}{3(2 k+1)}
$$

It is easy to get this sensitive coefficient will always be less than 1.

\section{CONCLUSIONS}

This paper discuss that common dilemma exists in economic transactions, when both parties who make deal and get benefits from the deal, but $f$ the transaction fails, his utility is nothing under private information.This problem can be solved by theory of incomplete information static game. In game model, the dominant agent of bargaining power play very important roles, we fortunately get some significant results as follow:

- Avoid the failing of transaction, the dominant agent $i$ will always be an overreaction in the transaction.

- Agent $\mathrm{j}$ will do the excessive reaction in the transaction; If $k>1 / 3$, and vice versa.
- $\quad$ the resulting transaction price will be more sensitive to the type of the dominant agent $\mathrm{i}$, if $\sqrt{2 / 3}>k>0$, the resulting transaction price will be more sensitive to the type of the dominant agent $\mathrm{i}$, if $1>k>\sqrt{2 / 3}$.

- Whatever the value of $\mathrm{k}$, the resulting transaction price will always be cautious to the type of the agent $\mathrm{j}$.

Using the method of game theory, this paper studied the trade both parties for their own trading valuation in the presence of private information, how to use a double auction strategy to determine the value of the transaction.

\section{References}

[1] Stephen A. R.. The economic theory of agency: the princioal's problem [J]. American wconomic association. 1973,63(2):134-139.

[2] Bengt Holmstrom. Moral Hazard and Observability The Bell Journal of Economics, 1979,10(1):74-91.

[3] Gan X, Sethi S P, Yan H. Coordination of Supply Chains with RiskAverse Agents[J]. Production \& Operations Management, 2004, 13(2): 135-149

[4] Corbett C J, Groote X De A supplier's optimal quantity discount policy under asymmetric information [J]. Management science, 2000, 46 (3):444

[5] Corbett C J, Zhou D, Tang C. S Designing supply contracts: contract type and information asymmetry [J]. Management Science, 2004, 50 (4) 550-559

[6] Cachon, G.P., 2003. Supply chain coordination with contracts. In: Graves, S., de Kok, T. (Eds.), Handbook in Operations Research and Management Science: Supply Chain Management. North Holland, Amsterdam. 